\title{
Роль генетических исследований в диагностике заболеваний височно-нижнечелюстного сустава
}

\author{
К. А. Семенов ${ }^{1}$ О. В. Деньга ${ }^{2}$, В. Н. Горохивский ${ }^{3}$ \\ ${ }^{1}$ Днепропетровская медицинская академия, г. Кривой Рог, \\ ${ }^{2}$ Институт стоматологии и челюстно-лицевой хирургии НАМН Украины, г. Одесса, \\ ${ }^{3}$ Одесский национальный медицинский университет

\section{The role of genetic investigations in diagnosis of diseases of temporo-mandibular joint}

\author{
K. A. Semenov ${ }^{1}$ O. V. Denga ${ }^{2}$, V. N. Gorokhivsky ${ }^{3}$ \\ ${ }^{1}$ Dnepropetrovsk Medical Academy, Krivoy Rog, \\ ${ }^{2}$ Institute of Stomatology and the Jaw-Fascial Surgery, Odessa, \\ ${ }^{3}$ Odessa National Medical University
}

\section{Реферат}

Цель. По результатам генетического исследования и их числового выражения подтвердить клинические диагнозы пациентов для дальнейшего составления плана лечебно-профилактической помощи.

Материалы и методы. В исследовании приняли участие 10 пациентов: 5 женщин и 5 мужчин в возрасте от 25 до 50 лет. Анализ проводили в лаборатории молекулярно-генетических исследований - ООО «Гермедтех», г. Одесса. Для выделения и очистки дезоксирибонуклеиновой кислоты (ДНК) из буккальных клеток использовали метод Деллапорта. Результаты. На основании результатов анализа генов GSTM1, CoL2A1, MMP1, ER, IL1B, TNF, участвующих в метаболизме костно-хрящевой ткани сустава, определен генетический риск развития заболеваний височно-нижнечелюстного сустава (ВНЧС).

Выводы. На основе генетического исследования по определенному набору генетических маркеров и их анализу уточнены и подтверждены клинические диагнозы. Определенный набор генетических маркеров и их цифровые значения позволяют составить прогноз течения патологического процесса и на основании этого проводить лечебные и профилактические мероприятия, разработать индивидуальный протокол лечения пациентов с заболеваниями ВНЧС.

Ключевые слова: заболевания височно-нижнечелюстного сустава; пациенты; результаты генетического исследования.

Abstract

Objective. In accordance to the genetic investigation results and their numerical value to confirm clinical diagnoses in patients for further adjustment of the treatment-prophylactic plan.

Materials and methods. In the investigation 10 patients took part: 5 women and 5 men, ageing 25 - 50 yrs old. Analysis was conducted in laboratory of molecular- genetic investigations - Ltd «Germedtech», City of Odessa. The Dellaport's method was applied for isolation and purification of deoxyribonucleic acid from buccal cells.

Results. Basing on results of the genes GSTM1, CoL2A1, MMP1, ER, IL1B, TNF analysis, taking part in metabolism of the joint osteo-cartilaginous tissue, a genetic risk of the diseases of the temporo-mandibular joint development was determined.

Conclusion. Basing on genetic investigation, concerning certain quantity of genetic markers and their analysis, clinical diagnoses were clarified and confirmed. Certain quantity of genetic markers and their numerical values permit to prognosticate the pathological process course, to conduct treatment and prophylactic measures and to elaborate individual protocol of treatment on this background in patients, suffering diseases of temporo-mandibular joint.

Keywords: diseases of temporo-mandibular joint; patients; results of genetic investigation.

Диагностика заболеваний суставов и суставных синдромов является актуальной задачей для современной терапии. Артрит, артроз, болевая дисфункция - наиболее распространенные заболевания ВНЧС. К возникновению патологических изменений в суставе приводит наличие первичного очага (очагов) воспаления инфекционной или травматической природы.

Одним из факторов развития патологии ВНЧС является наследственный дефект формирования соединительной ткани, наличие которого можно определить по генетическим маркерам. К генетическим маркерам, характеризующим предрасположенность и характер течения заболеваний ВНЧС, относят: изменения в гене коллагена типа II (COL2A1); мутацию в гене MMP1, мутацию в генах, координирующих состояние рецепторов эстрогенов ER $\alpha$ и ER $\beta$ в остеобластах и их физиологическую активность; экспрессию цитокинов, прежде всего ИЛ1 и TNFa, играющих большую роль в развитии морфологических изменений; мутацию в гене GSTM [1 - 4]. Для уточнения клинического диагноза проводили генетическое исследование. В соскобе буккального эпителия слизистой оболочки полости рта у пациентов определяли изменения в генах, характеризующих развитие или предрасположенность к развитию патологий ВНЧС. 
Цель исследования: по результатам генетического исследования и их числового выражения подтвердить клинические диагнозы пациентов для дальнейшего составления плана лечебно-профилактической помощи.

\section{Материалы и методы исследования}

В исследовании приняли участие 10 пациентов: 5 женщин и 5 мужчин в возрасте от 25 до 50 лет. Анализ проводили в лаборатории молекулярно-генетических исследований - ООО «Гермедтех», г. Одесса.

У каждого пациента делали соскоб буккального эпителия со слизистой оболочки полости рта. Эпителий собирали в пробирку Eppendorf со стерильным физиологическим раствором. Все полученные биоматериалы транспортировали в лабораторию в специальных термоконтейнерах при температуре $4{ }^{\circ} \mathrm{C}$. Выделение и очистку ДНК из буккальных клеток проводили по методу Деллапорта. Собранный материал тщательно перемешивали, отбирали 100 мкл в стерильную микропробирку, добавляли 1000 мкл лизирующего раствора Деллапорта, перемешивали на центрифуге вортекс Микроспин FV-2400 и инкубировали при температуре $65^{\circ} \mathrm{C}$ в течение 40 мин. После инкубации добавляли 285 мкл 5М калия ацетата и перемешивали на центрифуге вортекс Микроспин FV-2400. Инкубировали в течение 10 мин во льду. Центрифугировали 5 мин при ускорении 13000 об/мин на центрифуге Eppendorf 5424. Переносили весь супернатант в новую микропробирку, добавляли равное количество изопропанола, тщательно перемешивали на центрифуге вортекс Микроспин FV-2400. Инкубировали 30 мин в морозильной камере при температуре -20 С для преципитации ДНК. Центрифугировали 15 мин при ускорении 13000 об/мин для осаждения ДНК на центрифуге Eppendorf 5424. Удаляли супернатант. Добавляли 500 мкл 70\% этилового спирта к осадку ДНК. Перемешивали на центрифуге вортекс Микроспин FV-2400. Центрифугировали 5 мин при ускорении 13000 об/мин на центрифуге Eppendorf 5424. Удаляли супернатант. Добавляли 300 мкл ацетона. Перемешивали на центрифуге вортекс Микроспин FV-2400. Центрифугировали 1 мин при ускорении 13000 об/мин на центрифуге Eppendorf 5424. Удаляли ацетон как можно более полно и оставляли пробирку открытой. Подсушивали осадок в Dry Block 1 - 1,5 мин при температуре 50 C. Растворяли осадок ДНК в 100 мкл деионизованной воды. Перемешивали на центрифуге вортекс Микроспин FV2400. Определяли содержание ДНК на спектрофотометре (Nanophotometr, Implen), отобрав аликвоту 5 мкл непосредственно из пробирки с раствором ДНК.

Аллельные варианты генов CoL2A16846C>A, MMP11607insG, IL1B C3954Trs1143634, TNF G(-308)A Rs1800629 оценивали методом аллель-специфической полимеразной цепной реакции (ПЦР). Амплификацию исследуемых участков генов проводили параллельно в двух пробирках Eppendorf для нормального и мутантного варианта гена в 20 мкл буферного раствора (фирма «Fermtntas») и 100 нм каждого олигонуклеотидного праймера, 100 - 150 нг ДНК.

Аллельные варианты гена ER-альфа rs2234693, rs9340799 выявляли методом ПЦР-ПДРФ - (полимеразная цепная реакция полиморфизм длин рестрикцион- ных фрагментов), обрабатывая амплификаты ферментами рестрикции PvuII, XbaI.

Полиморфный вариант гена глутатион-S-трансферазы M1 (ген GSTM1) - наличие или отсутствие делеции определяли методом ПЦР с соответствующими праймерами.

ПЦР проводили на амплификаторе BIO-RAD (CША), экспериментально подбирали необходимую программу смены температур и длительности каждого шага реакции для определения полиморфизма исследуемых генов. Начальная денатурация при температуре $95^{\circ} \mathrm{C}$ в течение 10 мин. ПЦР в течение 40 циклов: денатурация при температуре $95^{\circ} \mathrm{C}$ в течение 30 с, отжиг при температуре от 55 до $65^{\circ} \mathrm{C}$ в зависимости от локус-специфических олигонуклеотидных праймеров в течение 30 с, элонгация при температуре $72{ }^{\circ} \mathrm{C}$ в течение 30 с, окончательная элонгация в течение 3 мин при температуре $72{ }^{\circ} \mathrm{C}$. Фракционирование продуктов амплификации проводили в горизонтальном 2\% агарозном геле, приготовленном на однократном трис-боратном буфере (1хТВE), при напряжении 100 В в течение 45 мин. Маркер молекулярного веса ДНК - pUC19: Msp1.

Агарозный гель окрашивали бромистым этидием и визуализировали в проходящем ультрафиолетовом свете.

\section{Результаты}

На основании результатов анализа генов GSTM1, CoL2A1, MMP1, ER, IL1B, TNF, участвующих в метаболизме костно-хрящевой ткани сустава, определен генетический риск развития остеоартрита и остеоартроза.

Для ревматоидного артрита характерно сочетание следующих показателей генетических маркеров: мутация в гене GSTM, который отвечает за синтез эпоксигидролазы, глутатионтрансферазы, глюкуронилтрансферазы, ацетилтрансферазы и др., превращающих токсичные промежуточные продукты метаболизма I фазы в полярные водорастворимые нетоксичные соединения - вторая фаза детоксикации; мутация в гене COL2A1; мутация в генах, координирующих состояние рецепторов эстрогенов ER $\alpha$ и ER $\beta$; мутация в гене IL1B, отвечающего за активность цитокинов.

Для болевой дисфункции суставов характерны мутация в гене GSTM1, отвечающем за синтез ферментов, превращающих токсичные промежуточные продукты метаболизма I фазы в полярные водорастворимые нетоксичные соединения - вторая фаза детоксикации; мутация в гене ER, приводящая к нарушению состояния рецепторов эстрогенов в остеобластах, что влияет на их физиологическую активность и тем самым отражается на метаболизме костной ткани.

Для артроза характерны мутация в гене ММР1, отвечающего за синтез и активность металлопротеиназ, при их накоплении происходит первичная деградация молекул коллагена; мутация в гене ER Xbal и мутация в гене IL1B, отвечающем за активность цитокинов.

Для артрита характерны мутация в гене COL2A1, отвечающем за качественный состав коллагена; мутация в гене IL1B, отвечающем за активность цитокинов. Провоспалительные цитокины, которые угнетают образование матрикса хряща, стимулируют синтез металлопротеиназ 
и снижают продукцию тканевых ингибиторов матриксных протеиназ.

Анализ суммарного набора мутированных генов позволяет распределить пациентов и выявить обратимость и необратимость патологических изменений вследствие развития патологического процесса и в дальнейшем составить индивидуальный протокол лечебно-профилактических мероприятий при заболеваниях ВНЧС. Аллели нормы оценивали в 1 балл, гетерозиготы - в 2 балла, мутации - в 3 балла. Результаты мутаций генов представлены на гистограмме (см.рисунок).

По клиническим наблюдениям наличие мутаций, оцененных количеством баллов от 6 до 9, свидетельствует об обратимости процессов и стойкой ремиссии при проведении лечебно-профилактических мероприятий в зубочелюстном аппарате. При наличии мутаций, оцененных в 9 и выше баллов, требуется консультация смежных специалистов для нормализации минерально-обменных процессов организма.

В исследованной группе пациентов ревматоидный артрит диагностирован у 2 (20\%), болевая дисфункция ВНЧС - у 2 (20\%), артроз - у 3 (30\%), артрит - у 3 (30\%).

\section{Обсуждение}

Ревматоидный артрит - аутоиммунное заболевание неизвестной этиологии, для которого характерно симметричное поражение хрящевой и костной ткани [5]. Это системное заболевание соединительной ткани преимущественно поражает мелкие суставы по типу эрозивнодеструктивного полиартрита неясной этиологии со сложным аутоиммунным патогенезом, нередко сопровождается развитием широкого спектра системных проявлений. У большинства пациентов ревматоидный артрит имеет хроническое течение и без своевременного лечения приводит к деформации и нарушению функций суставов, ухудшению качества жизни $[1,3,4,6]$.

Заболевание может появиться в любом возрасте, более распространено среди женщин, чаще всего поражает кисти, пальцы, колени, стопы, локти. Точная причина заболевания неизвестна. При аутоиммунных заболеваниях, к которым относится и ревматоидный артрит, иммунная система воспринимает здоровые ткани как чужеродные агенты и борется с собственным организмом. Кроме того, изучается роль широкого спектра инфекционных и неинфекционных факторов, которые могут опосредованно участвовать в развитии ревматоидного артрита на фоне генетической предрасположенности. К этим факторам относятся: вирус Эпштейна-Барр, парвовирус В19, ретровирусы, антигены и стрессовые белки бактерий, курение, угольная пыль, лекарственные вещества, некоторые компоненты минеральных масел, различные химические соединения [5].

Болевая дисфункция ВНЧС - это патология, характеризующаяся нарушением нервно-мышечного механизма, регулирующего все суставные движения. Нарушения окклюзии (смыкания зубов) могут возникнуть вследствие отсутствия зубов, аномалий прикуса, неправильного зубопротезирования и других факторов. При окклюзионных патологиях наблюдаются изменения в характере

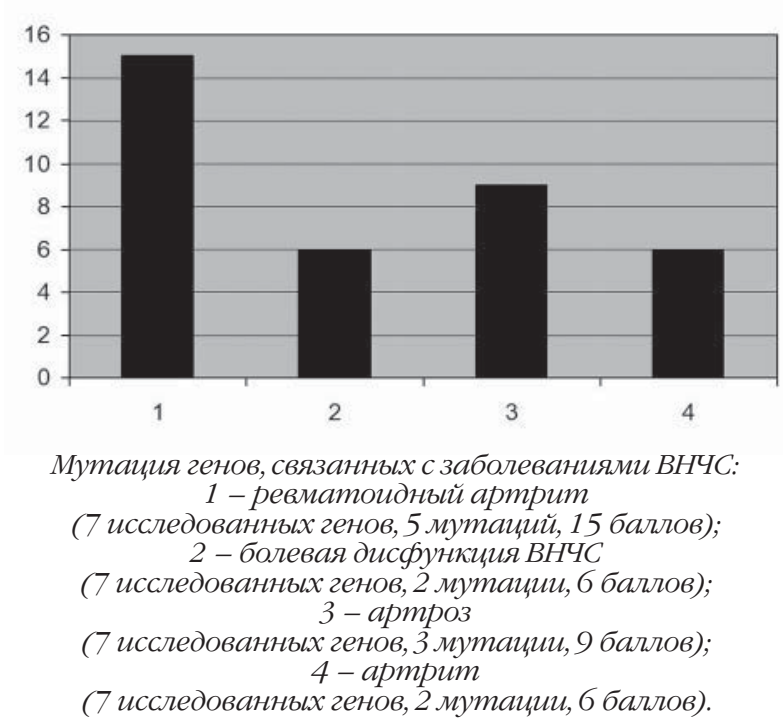

жевания, что приводит к постоянному перенапряжению жевательных мышц с одной стороны и их несинхронному сокращению. Все это вызывает разбалансированность в суставе [2].

В результате психогенных факторов (стрессы) развиваются состояние с сильным сжатием зубов и, соответственно, мышечный спазм. Учеными доказано, что более половины пациентов с болевой дисфункцией ВНЧС имеют психогенные или неврогенные нарушения. Скрежет зубами (бруксизм), в результате которого наблюдается повышенная активность жевательных мышц и происходит стискивание зубов, нередкая причина развития данного заболевания.

Всем больным с жалобами на боль в ВНЧС необходимо проводить его панорамную рентгенографию. Данная патология не характеризуется рентгенологическими изменениями костной ткани суставных головок нижней челюсти, однако нередко определяется их асимметричное положение и различная ширина суставной щели слева и справа [5, 7].

Артроз развивается, когда хрящ и субхондральная кость не способны адекватно противостоять механической нагрузке, что связано с ограничением репаративных возможностей этих тканей $[5,7]$. Развиваются патологические изменения в основном гиалинового хряща, в котором не только уменьшается количество хондроцитов, но и снижается их метаболическая активность. Это приводит к снижению синтеза коллагена в матриксе хряща и сульфатированных протеогликанов - хондроитина сульфата, кератана сульфата, протеогликан-гиалуроновых агрегатов, а также гиалуроновой кислоты. Наиболее важной составляющей этих изменений является дефицит синтеза протеогликанов - основного структурного компонента матрикса хряща. При артрозе не только снижается количественный синтез протеогликанов, но и изменяется их качественный состав, а именно выработка полноценных протеогликанов с высокой молекулярной массой $[4,8,9]$.

Артрит представляет собой гетерогенную группу заболеваний с воспалительно-дегенеративными изменениями всего тканевого комплекса сустава: хрящевой ткани, 
субхондральной кости, синовиальной оболочки, связок, капсулы, периартикулярных сухожилий и мышц, но наиболее серьезные изменения происходят в хрящевой ткани [3]. Испытывающая значительные механические нагрузки хрящевая ткань вынуждена постоянно самообновляться, что обеспечивается системой хондроцитов. Их функция - обновление соединительнотканного матрикса, главными компонентами которого являются коллаген и протеогликаны. При артрите обновление хондроцитов нарушено и, как результат, деструктивные процессы в матриксе преобладают над восстановительными $[5,7]$.

\section{Выводы}

1. На основе генетического исследования по определенному набору генетических маркеров и их анализу были уточнены и подтверждены клинические диагнозы.

2. Определенный набор генетических маркеров и их цифровые значения позволяют составить прогноз течения патологического процесса и на основании этого проводить лечебно-профилактические мероприятия, разработать индивидуальный протокол лечения пациентов с заболеваниями ВНЧС.

\section{References}

1. Baranov VS, Baranova EV, Ivashhenko TE, Aseev MV. Genom cheloveka i geny «predraspolozhennosti» (vvedenie v prediktivnuju medicinu). SPb.: Intermedika; 2000. 272 s. [In Russian].

2. Zhelenina LA, Ivashhenko TE, Efimova NS. Polimorfizm genov semejstva glutation-S-transferazy (GST) pri bronhial'noj astme u detej. Allergologija. 2003;2:13-6. [In Russian].

3. Zazerskaja IE, Aseev MV, Kuznecova LV, Moskalenko MV. Analiz associacii allelej gena COL1A1 s razvitiem osteoporoza. Genetika. 2002;38(12):1699-703. [In Russian].

4. Pantsulaia I, Trofimov S, Kobyliansky E, Livshits G. Genetic and environmental influences on IL-6 and TNF-alpha plasma levels in apparently healthy general population. Cytokine. 2002;19(3):138-46. doi:10.1111/ j.1365-2265.2006.02456.x

5. Timofeev AA. Rukovodstvo po cheljustno-licevoj hirurgii i hirurgicheskoj stomatologii. Kiev: OOO «ChervonaRuta-Turs»; 2004. $1062 \mathrm{~s}$. [In Russian] ISBN 966-8607-00-7.

6. Rovetta G, Grignolo MC, Buffiini L. Prevalence of C282Y mutation in patients with rheumatoid arthritis and spondylarthritis. Int J Tissue React. 2002;24(3):105-9. PMID:12635863.

7. Kljajnrok M. Funkcional'nye rasstrojstva v dvigatel'noj chaste zhevatel'nogo apparata. L'vov: «GalDent»; 2015. 256 s.[In Russian] ISBN 978-966-7337-62-9.

8. Alvim-Pereira F, Alvim-Pereira C, Trevilatto P. The Current Knowledge of Genetic Susceptibility Influencing Dental Implant Outcomes. The International journal of oral \& maxillofacial implants. 2011:347367. doi: $10.5772 / 18065$.

9. Grant SF, Reid DM, Blake G. Reduced bone density and osteoporosis associated with a polymorphic Sp1 binding site in the collagen type I alpha 1 gene. Nat Genet. 1996;14:203-5. doi:10.1038/ng1096-203. 